\title{
Writing and Designing a Book about Design and Designing for Young Designers: People who don't like to Learn by Reading.....and the lessons learned along the way.
}

\author{
Brian Burns \\ Associate Professor, Industrial Design and Environmental Science \\ Carleton University, Ottawa, Ontario K1S 5B6 \\ brian_burns@carleton.ca
}

\begin{abstract}
Writing a book for design students based on a range of lessons, maxims and wisdoms that had been accumulated over thirty years in the field seemed like a valid exercise. Unfortunately the task was made initially difficult by the simple realization that designers, who many consider to be visual thinkers, tend not to look to books in their attempts to learn how to design. This realization led, eventually, to the choice of a particular format, though with the added realizations that, while, in the past, we have predominantly looked to traditional formats for the creation of texts, papers and books in Engineering, Design and Science, the developments in our technological capabilities for storing and retrieval of information have, quite recently, changed, perhaps forever, how we choose to access all forms of information. The danger now lies in writing for the sake of recording research activity, and in not writing for effective communication, with due consideration for the implications of the chosen media, the time availability, level of comprehension, and the mode of preferred comprehension of the reader. Tradition is strong in the creation of the written word, but we appear to have passed through what could be described as a 'tipping point', which now offers a unique opportunity to encourage and promote more effective modes of communication; more dynamic, interactive, visual, in the appropriate format and location, 'accurate, brief and clear', and just when it is needed.
\end{abstract}

Keywords:

Communication: Written formats: Learning Design: Tipping Point: Digitization of Information: Social Change: Liquid Books:

\section{INTRODUCTION}

After a period of thirty plus years involved in the education of university industrial design students I had learned a number of important lessons that I had found useful in helping students learn their craft. While there are many classic design texts, and I had accumulated a number of these, I felt that there was a need to pass on the lessons that had proven useful in some appropriate form. I was aware that designers traditionally don't like to read, nor do they particularly learn by reading, so the choice of medium, style and format were quite important. After much deliberation, which will be the initial focus of this paper, the result was a paperback book of approximately 170 pages containing approximately 180 'bite-sized' sections of average length 250 words; with no images or diagrams.

The rational for this choice was based on a number of key decisions which are explained below. However, the process of determining the format led to the realization of a number of important issues in the development of all written work intended for communication, and the realization that we might have already passed what Malcolm Gladwell ${ }^{\mathrm{i}}$ might term a 'tipping point' in the design and development of written material. In essence, the ease with which it is now possible to create written material, thanks to technological and digital developments, both virtual and physical, we now have a plethora of sources of information that make it very difficult for anyone to know when and where to start and stop researching. It has also encouraged the practice of looking for information only at the time of need and in the media of the user's choice; which is now less likely than ever to be in printed text format. In essence being able to write is now very easy, but to be successful, the design and format of what is intended to be communicated should now be determined more by the specific attributes of the reader.

As a consequence, in the $21^{\text {st }}$ century our traditional vehicles of written communication are being challenged by all manner of electronic media. No longer simply trying to support the status quo of communications, now we are a wide variety of frequently preferred alternative modes of communication, which represent a fast changing 
literary environment. Clinging on to traditional documents may well be more for tradition than successful communication. Indeed, the author questions whether this paper is the appropriate form for this 'discussion' paper. Who will read it, and how would it better reach those who are interested or would benefit most from the questions it poses? But before getting to those issues we will first go over the events that sparked this paper.

\section{WHY WRITE A BOOK ABOUT DESIGNING?}

A lengthy career in any profession is likely to yield some important lessons along the way. For myself, many of the lessons I learned were quite painful. The notion of making all the 'lessons and wisdoms' that I wished I had been told about when I was starting out available to young design students, seemed an obvious one. A further literature search showed a wide range of books about design, but only a very few that attempted to tackle this need in students. However, this was where the design of such a text started to become interesting.

Many years ago, as a young designer, I was informed by my professor that industrial designers are visual people, and that for design, a picture is worth a thousand words. While the lessons intended to be passed on were derived from a career largely focused on experiences in industrial design, the principles were generally far broader, and were felt to be applicable to a range of design challenges. While many academics are able to surround themselves with books of note, while I was learning how to design it was clear that books telling people how to develop ideas, concepts, to develop skills in thought an action were not generally available. Though everyone seemed to have one or two favourite texts, Design, it would appear, is felt to be an act of personal synthesis. The intent of any design activity is always to tread into unknown territory. For this it is assumed that design is not then a formulaic act, and thus learning how to design needs to be respectful of the human process.

An early assumption was that while there are some 'classic' design texts, the personal journey to become a designer was not found to be well addressed in book form, nor electronically. In the fast changing world of design in the $21^{\text {st }}$ century, building the bridge between experience and the best of practice in design is becoming a very delicate challenge. Young designers easily tire of seeing 'last year's designs' as examples for their future projects. This makes slightly ancient case studies appear irrelevant, even if still pertinent. While eBooks are starting to show popularity, the paperback requires no batteries or special software, and since this book was first planned to be tested, the notion of an initial paperback print version of 100 copies was felt appropriate.

\subsection{Visuals, Format, Sections, 'Dipinability', and Length}

While fundamental texts exist detailing the so-called 'Design Process', the most common and popular material to help designers learn how to design, involves the use of the previously mentioned case studies; with their inherent concerns for relevance and the maintenance of currency. Thus, acknowledging the remarkable capacity of 'Google'-type searching, and the ever expanding images and films available through YouTube, an early decision was made not to include images within the text, offering the reader the opportunity to look for more visual and other information as and when they wished to look for it.

A number of print formats were considered which led to a desire to make the book physically easy to read, unpretentious and largely non-academic. This involved the selection of the Melior 10pt font with a words-per-line ratio of about fourteen. The overall size of the book became 8.6 x 6.6 inches, based on a general analysis of similarly intended books.

The next challenge related to the question of whether the reader should be required to read the book from start to finish and in its entirety. Many handbooks came to mind, and with them a sense that once the spirit of the book was understood then the reader should be allowed to 'dip into' the book, when and where they wished. While reaching this decision it was realized that most documents, aside from novels, are today 'dipped-into'; text books, articles and reports.

It should be added that these decisions were taken over one or two years, which aided in the gestation of what was thought would be the final format, but also allowed the author to accumulate and organize the issues that would form the content of the book.

In July 2011 the book was published by Buschek Books of Ottawa. Some were offered to students, and some were sent to colleagues around the world for their input. Feedback has been generally very good, but it was realized that such a book has a limited market. At the time of writing the second edition, with only slight modifications to the original version, is being printed in quantities up to 500. Already there are tentative plans to make it into an eBook, and the whole experience has led to me to question everything I have written and might write in the future.

\section{WHAT IS THE ESSENCE OF COMMUNICATION AND WHEN IS IT NEEDED?}

In the past even Aristotle was mocked for his attempts to assemble his own library. Many of us now keep our paperbacks, reference books, old favourite texts, journals, 
magazines, and articles in our own libraries. At the same time academics commonly 'battle' with their students and even their colleagues, who are all too often felt guilty of quickly leaping to the least accurate sources of internet information for apparent truths to justify their work.

As a natural consequence, our libraries have immersed themselves in the process of formulating credible data and literature bases with accessible sources, based on key words, abstracts and titles. These are increasingly easy to access, as long as you have the required permission. But, this may be merely an extension of the past; taking traditional modes of communication and putting them in a modern electronically based format. The question occurred; is this how we should best address knowledge and learning with the technological knowledge bases, social changes, and lifestyles that we are now developing?

Research that once relied simply on access to books is a thing of the past. When we relied solely on books and journals/magazines, research access was more limited, while the difficulty and control over published material helped foster some form of quality control. All the while, the printing process was king; fonts and page size ruled.

Winston Churchill ${ }^{\mathrm{ii}}$ offered much wisdom during his lifetime. Some 50 years ago he suggested that there is nothing that cannot be summarized on a single sheet of foolscap paper. He also chastised a colleague for their report, "the length of this document defends it well against the risk of being read". These wisdoms and witticisms were landmarks in our desires to accumulate knowledge and wisdom since they reflected, perhaps for the first time, not just the importance of page format and font size, but how much time the reader would have to take in the written work.

It is arguable that as we are all now able to write more and duplicate our work in many formats with almost limitless availability, the time for the reader to read, comprehend and act has diminished at the same rate. The future of communication cannot simply be the past extended. If a tipping point indeed existed, we are now well past it, and we must holistically embrace the opportunities we are presented with.

\subsection{Traditional vs. $21^{\text {st }}$ century Communication}

In the evolution of knowledge we have always had to accommodate the limitations of appropriate technological capability. Perhaps this is why the development of the printing press is heralded by so many as the greatest achievement of civilization. The twentieth century has brought about many refinements in the production of journals, books and all manner of texts, advanced library access, photocopiers, and most recently key word searches.

In the $21^{\text {st }}$ century, the personal computer is the tool of choice. The word 'Google' has been in the Oxford English
Dictionary as a verb since 2006, and soon it will be followed by 'Face book' and 'Twitter', and the current research and information sharing tools of choice.

Even with the 'qwerty' keyboard, the format of the page has often changed to horizontal (screen shaped) rather than vertical, though 'kindle-tablet devices still offer the format of the vertical page (including simulated page turning). Beyond making specific reading mandatory in our academic courses, we now have to be realistic in our hopes for student research methodology. How much material can we actually research, of the vast amounts being generated and, more importantly, becoming available in ever increasing quantities every day?

Communication is fundamentally a process to bring about change; whether this is simply by increasing knowledge or by encouraging a change in action. It is not enough merely for written work to be read and understood, and it is increasingly not a one-way street. This realization makes any reliance solely on the traditional printed word potentially obsolete.

\subsection{Changes in the Science of Communication and the Communication of Science.}

The importance of communication of Science and, as a direct consequence, Engineering and Design, has grown in the past 50 years. Perhaps this is due to environmental concerns, perhaps due to political involvement in scientific issues, perhaps due to changes in global patterns, perhaps due to global recessions; whatever the reasons the growth in concern for better communication of the broad field of science has grown. The publication of 'The Visible Scientists' in $1977^{\mathrm{iii}}$ was as a direct consequence of the need and the accompanying lack of involvement in the process by those responsible. In many ways this was a beginning of the active involvement of both journalists and the media in the broad field of scientific research and development ${ }^{\text {iv }}$. Much of this work focused on issues akin to those of engineering - the need for Legitimacy, Interdisciplinarity, and Clearer Access to Concepts and Processesv. Since then we have seen a number of attempts to popularise science with ongoing conflicts $^{\mathrm{vi}}$ (Handbook of Public Communication of Science and Technology) between journalists and scientists/technologists. In some instances the scientific community saw the move to 'popularise' science as a 'revolt' 'vii . At the same time the access to the Web seems to have launched a fear or prediction that the 'new media' would inevitably result in a growth of uncertainty ${ }^{\text {viii }}$.

More recently efforts to encourage communication in science and engineering prompted an essay in the New York Times that made the comparison between the similarities of the values of science and engineering and democracy - "honesty, doubt, respect for evidence, 
openness, accountability and tolerance, and the hunger for opposing points of view,"ix

Interest in the subject of communication continues to grow, with scientists and engineers engaged in extensive dialogue concerning the path forward ${ }^{\mathrm{x}}$ (Taking Science to the People), with increasing numbers of scientists and engineers acknowledging the opportunities and obligations and the need to improve personal skills in communication.

\subsection{The Power of the Visual.}

There is a rich and long tradition in the visual communication of science, engineering, and technology. David Ehrenstein calls this 'Picture Power', when complex abstract concepts can be better communicated by an image - making science visible ${ }^{\mathrm{xii}}$.

'Mental images are a great way to make complicated concepts seem simple, skip over wordy explanations, make stories come alive, and allow stories to jump straight to the physical principle without a lot of preliminary terminology. If a physics story seems wordy and abstract, it can usually be improved by adding a clearly drawn mental image. ${ }^{\text {xiii }}$ (p.79)

The new media now offer us the opportunity to explore visual communication. After all, the use of words to explain a concept is in itself an abstraction, now we can offer the reader to chance, as Will Rogers ${ }^{\text {xiv }}$ reminded us, to learn by peeing on the electric fence oneself.

\subsection{But how much time do you have - to write and to read?}

In his recent novel, 'The High Road'xv, Terry Fallis makes reference to the often quoted Mark Twain adage (interestingly George Bernard Shaw developed the same adage), in which he apologises for writing a long letter because he did not have time to write a short one. In the same novel, Fallis writes of concerns for not just writing short enough, but also in the need to write even political documents in the language of the people. The document in question is constructed and edited to reduce what was originally a 40 page document to just 22 .

This is the reality. If communication in science, engineering and design is to promote change in knowledge, learning, and behavior with the increasing need for on-going dialogue, then it may well need to be written shorter (perhaps even visually) in the medium of choice, in order to match the time and knowledge realities of the reader.

\section{A POSSIBLE PRESCRIPTION FOR COMMUNICATION IN THE $21^{\text {st }}$ CENTURY}

The task of writing with interdisciplinary awareness now centers on a growing list of important decisions. Here are some suggestions:

1. Do we really need to write something or would another medium be more effective.

Writing was invented because we couldn't communicate an event or an idea to more than an immediate group of people any other way. Writing was the best we could come up with, but we should remind ourselves just how telegrams, letters, and newspapers have suffered the consequences of the development of a more direct mode of communication. Perhaps there is a better way.

2. How much time does the reader have?

Just as Winston Churchill praised the summarizing of 'anything' onto a single side of foolscap, there is the adage that one page will be read today, and two pages will be read tomorrow; and tomorrow never comes! We hear of 'the two minute elevator pitch' to a potential client, and the ' 20 second sound bite'. Beyond reading a novel for pleasure, most reading is means to an end, and knowing the time that a reader is prepared to give up is essential.

3. What is the educational level of the reader?

Formal report writing evolved the 'Glossary' to help the reader with key words or expressions. In Science and Engineering, for example, often written work is passed between colleagues of equal academic standing. However, the research and problem solving of today is both multidisciplinary and multi-personal with the consequences of work being communicated to a range of readers. Science and Engineering currently suffer from a perceived problem of communication at a time when good science and good engineering are essential. Commonly the communication of science to non-scientists and engineering to non-engineers is passed off to a writing specialist, and all too often something appears to get lost in the translation.

4. What change is the work trying to bring about?

While I enjoy the process of writing to help me organize my thoughts and findings, but that is not why I offer it for communication. In writing this paper I am conscious of the change I am trying to help bring about in the reader.

5. Will communication need to be two-way?

The advantage of the telephone over email is that it contains intonation and both parties are engaged 
in dialogue. This is a disadvantage of all written work. We are fortunate that so much digital media encourages two-way communications. A novel is a novel, but most other written work forms part of a dynamic communication stream.

6. How does the "reader" best take in information? Just as a conceptual or visual designer may not like to read from texts, every reader in every profession will have their own preferred mode of communication, and increasingly this will not rely solely on the printed word.

7. Does the information need to be stratified?

This paper as with many reports is stratified and structured. It reflects that some will glimpse at a title, some of those will read the abstract, and some of those might jump to the conclusion or even the booklist. The idea that one level is all that is required to communicate information to the audience will likely be just as untrue of the report you might be reading now. This appears to be one of the challenges that the new media are tackling today, and the same issues are becoming increasingly relevant in education.

8. Will more than one person be reading the material for differing perspectives or issues?

Most reports are today multidisciplinary. For that the contents page has become particularly important, to help the readers find the sections that are significant to their interests. The same will be true of all communication media, but now digitization can help by offering depth and parallel messages imbedded in the same file.

9. Will the work be 'dipped into'?

While some work can be written simply for one 'type' of reader, anything of variable content or 'readership' will likely be 'dipped into'. Less and less written work is read from 'cover to cover', thus designing for this option is yet another exciting possibility.

10. When will the work become obsolete?

Just as every student finds references to dated files and images off-putting, the same fate is likely for much of today's 'written work'. While a great deal of traditional core material and texts will remain vital to any learning process, the challenge and opportunity exists to combine core fundamentals with today's dynamic examples.

One current initiative uses, what is termed, 'Liquid Books ${ }^{\text {xvi }}$. In such a 'book' publishers can pool their resources to create a dynamic, constantly updating 'text' in which the reader can add and contribute to its on-going use and understanding.

11. Will a traditional mode of communication be essential, even as back-up?
The emergence and disappearance of all manner of languages and vehicles for data storage - from punch cards to floppy discs to compact discs - has been remarkable in the last 30 or so years. So much data is now almost impossible to access. Is it lost forever? Some of our oldest documents, printed on hemp paper, will be with us for a long time, and long after the last compact disc disappears from our collections. Ironically, we always seem to need the back-up of what E.F. Schumacher termed 'primary technology'xvii; in this case the printed word.

12. Can an alternate mode be more effective, e.g. photograph, video, 3 dimensional representation, sound-bite?

As this list evolved, it became increasingly more difficult to use the 'written word' as the base model. Just as music was first oral, before being written down, we no longer have to use words to describe the scene; a photograph or even a video can be attached. While the sense of smell remains obscure to this process, so much more of the transfer of information can follow the techniques of the oral and visual; hopefully, with nothing being lost in the process.

13. How can the current modes of digitized communication be utilized appropriately without risk or ambiguity?

We can no longer deny the power or importance of the social media. The complications and potential for abuse and misuse are unfortunately obvious. These are new technologies which are growing in their popularity exponentially. Some would argue that the traditional media have always been effective, but the author suggests that the 'tipping point' in communication has long passed and we should now embrace all the potential of communication that modern technology and social change has brought about. Technology Push and Demand Pull in communication are both moving in the same direction.

\section{IN CONCLUSION}

This paper could perhaps be the last formal paper that this author will ever produce. In many ways the author hopes so. The experience of writing such papers has always helped clear the thought process for the author, but in many cases, writing a paper to be included in conference proceedings has never felt to be very effective.

Currently the vehicles for communication are somewhat disconnected, and combine the best and the worst of both ancient and modern methodologies. While the author fully appreciates the virtues of the novel and 
the potential for the real and synthesized printed word, it should be remembered that the early Gregorian chants were not written down, and that the evolution of the written word was to represent that which could not be seen, experienced or transported any other way.

Today, thanks to Skype, Face book, Google, YouTube and even the Ted Talks, we can be almost anywhere in the world at any time, and we can record our thoughts and ideas in all manner of ways.

A principle challenge is perhaps a reflection of something that found its way into the book that was the subject of this paper. I include a 'bite-sized' section of the book $^{\text {xviii }}$ that led me to write this paper.

\section{Wisdom, Knowledge, Information,}

Data, Stuff and \#*!?/.

'T.S. Eliot once wrote of the challenge of finding knowledge lost in the information, and wisdom, lost in the knowledge. We all aspire to wisdom in a society which ascribes to the importance of knowledge, but is increasingly inundated with information in unqualified amounts.

This dilemma led me to the awareness of a kind of hierarchy. At the top is wisdom, followed by knowledge and information - I could not disagree with T.S. Eliot, but I was struck by the new categories we seem to have created. Below information we have created data (in large amounts), and below data we have created stuff (in larger amounts), and below stuff we seem now to be creating \#*!? (indefinable and in even larger amounts).

So we now have: Wisdom

$$
\begin{aligned}
& \text { Knowledge } \\
& \text { Information } \\
& \text { Data } \\
& \text { Stuff } \\
& \text { \#*!? }
\end{aligned}
$$

In the process of making sense of information, often contradictory, instead of helping to forge a path towards wisdom, we often seem to be moving the other way: towards stuff and beyond. I encourage the reader, whenever engaged in a decision making process, to question whether the information they are trying to make sense of is leading them towards knowledge and wisdom or in the opposite direction.'

Perhaps a conference gathering similar to the one this paper was prepared for will, in future, have a more effective mode of formal communication than a 'camera ready' paper and the obligatory 15 minute (plus questions) PowerPoint presentation as the vehicles of choice....I look forward to such gatherings with eager anticipation. Until then, this was the best I could offer.

\section{References}

[1] Malcolm Gladwell, The Tipping Point: How little things can make a big difference. Little Brown, Boston, 2000.

\{ISBN 0316316962$\}$

[2] Winston Churchill (1874 - 1965), www.brainyquotes.com , accessed May 2012.

[3] Rae Goodell, The Visible Scientists. Little Brown, Boston, 1977. \{ISBN 9780316320009$\}$

[4] Ed. LeeAnn Kahlor and Patricia A. Stout, Communicating Science: New Agendas in Communication, Routledge, London and New York, 2010 \{ISBN 0415999596 \}

[5] ibid.

[6] Ed. Massimiano Bucchi and Brian Trench, Handbook of Public Communication of Science and Technology. Routledge International, London and New York, 2008

\{ISBN 9780415386173 \}

[7] ibid.

[8] ibid.

[9] Denis Overbye, For the Love of Physics, New York Times, Dec 2000.

[10] Ed. Carolyn Johnsen, Taking Science to the People: A communications primer for scientists and engineers, University of Nebraska Press, Lincoln and London, 2010

\{ISBN 978080322052 2\}

[11] ibid.

[12] ibid and Ed. Luc Pauwels, Visual Cultures of Science; Rethinking Representational Practices in Knowledge Building and Science Communication, University Press of New England, Hanover and London, 2006 \{ISBN 978158465512 1\} .

[13] ibid [10].

[14] Will Rogers (1879 - 1935), www.brainyquote.com, accessed May 2012

[15] Terry Fallis, The High Road, McLelland and Stewart, Toronto, 2010 \{ISBN 9780771047879 \}

[16] Open Humanities Press via University of Michigan's MPublishing, contact c.s.birchall@kent.ac.uk, 2012

[17] E.F. Schumacher, Small is Beautiful: A study of economics as if people mattered, UK, Blond and Briggs, 1973

\{ISBN 100060916303$\}$

[18] Brian Burns, People Want Toast notToasters: Lessons and maxims in learning design and designing, BuschekBooks,

Ottawa, 2012 \{ISBN 9781894543729 \} 